\title{
Faktor-faktor yang Memengaruhi Efektivitas Sekolah dengan Kemandirian Sekolah sebagai Variabel Intervening menggunakan Pendekatan Partial Least Square
}

\author{
Arie Wibowo Khurniawan ${ }^{1}$, Illah Sailah, Pudji Muljono ${ }^{1}$, M. Syamsul Maarif ${ }^{1}$, Bambang Indriyanto ${ }^{1}$ \\ ${ }^{1}$ Bogor Agricultural University
}

\begin{tabular}{l}
\hline \hline INFO ARTIKEL \\
\hline Riwayat Artikel: \\
Diterima: $10-02-2020$ \\
Disetujui: $18-07-2020$ \\
\hline
\end{tabular}

\section{Kata kunci:}

effectiveness of school; partial least squares structural equation modelling; school independence; vocational high schools

\author{
Alamat Korespondensi: \\ Arie Wibowo Khurniawan \\ Manajemen dan Bisnis \\ Bogor Agricultural University \\ Kampus IPB Gunung Gede, Jl. Raya Pajajaran, Bogor, Jawa Barat \\ E-mail: arie_wibowo@apps.ipb.ac.id
}

\begin{abstract}
The government encourages Vocational High Schools to carry out organizational transformation to become Regional Public Service Bodies. Through BLUD, SMKs with superior products can manage finances and production processes more flexibly without violating regulations so that school effectiveness can be achieved. This study aims to analyze the factors that influence SMK-BLUD schools' effectiveness through school independence using partial least squares structural equation modeling (PLS-SEM) analysis. The data were obtained by distributing questionnaires to 231 respondents from students, teachers, school principals, and committees in 25 SMKBLUDs in East Java and DKI Jakarta. It is known that the variables focus on customers, focus on processes, and continuous improvement have a positive and significant impact on school effectiveness. In addition, the independence of each school indirectly also has a positive and significant effect on school effectiveness. The results of this modeling show the value of Predictive Relevance (Q2) of 0.965, meaning that this model has a good Predictive Relevance.
\end{abstract}

ABSTRAK

\begin{abstract}
Abstrak: Pemerintah mendorong Sekolah Menengah Kejuruan (SMK) melakukan transformasi organisasi untuk menjadi SMK Badan Layanan Umum Daerah (SMKBLUD). Melalui BLUD, SMK yang memiliki produk-produk unggulan dapat mengelola keuangan dan proses produksi secara lebih fleksibel tanpa melanggar peraturan sehingga efektivitas sekolah dapat tercapai. Penelitian ini bertujuan untuk menganalisis faktorfaktor yang memengaruhi efektivitas sekolah SMK-BLUD melalui kemandirian sekolah menggunakan analisis PLS-SEM. Data diperoleh melalui penyebaran kuesioner kepada 231 responden dari siswa, guru, kepala sekolah, dan panitia di 25 SMK-BLUD di Jawa Timur dan DKI Jakarta. Diketahui bahwa variabel fokus pada pelanggan, fokus pada proses, dan perbaikan berkelanjutan memberikan pengaruh yang positif dan signifikan terhadap efektivitas sekolah. Selain itu, dengan adanya kemandirian setiap sekolah, secara tidak langsung juga memberikan pengaruh yang positif dan signifikan terhadap efektivitas sekolah. Hasil pemodelan ini menunjukkan nilai Predictive Relevance $\left(\mathrm{Q}^{2}\right)$ sebesar 0.965 , artinya model ini memiliki Predictive Relevance yang baik.
\end{abstract}

Dalam mewujudkan pengelolaan sekolah yang baik dibutuhkan suatu standar khusus agar terjadi pemerataan di tiap sekolah. Standar Pengelolaan Pendidikan diatur dalam Peraturan Menteri Pendidikan Nasional Nomor 19 tahun 2007. Peraturan Menteri tersebut terdapat hal-hal yang harus diperhatikan dalam pengelolaan pendidikan, seperti perencanaan program, pelaksanaan rencana kerja, pengawasan dan evaluasi, kepemimpinan sekolah, sistem informasi manajemen, dan penilaian khusus. Tertuang pula dalam Peraturan Pemerintah Nomor 19 Tahun 2005 tentang Standar Nasional Pendidikan Pasal 49 s/d 58 yang mengatur tentang standar pengelolaan pendidikan oleh satuan pendidikan yang berkaitan dengan perencanaan, pelaksanaan, dan pengawasan kegiatan pendidikan pada tingkat satuan pendidikan agar tercapai efisiensi dan efektivitas penyelenggaraan pendidikan.

Sekolah dikatakan efektif ketika prosesnya menghasilkan hasil positif yang dapat diamati (tidak selalu dapat diukur) dalam populasi siswa secara konsisten selama periode waktu tertentu (Alobiedat, 2011; Reynolds, 1994) (Alobiedat, 2011; Reynolds, 1994). Pada sekolah efektif seluruh siswa tidak hanya yang memiliki kemampuan tinggi dalam belajar, tetapi juga memiliki kemampuan intelektualitas yang biasapun dapat mengembangkan dirinya sejauh mungkin jika dibandingkan dengan kondisi awal ketika rnereka baru memasuki sekolah (Sulfemi \& Mayasari, 2019) (Sulfemi \& Mayasari, 2019). Sekolah yang 
efektif tercermin dalam lima karakteristik, yakni kepala sekolah yang memiliki kepemimpinan yang kuat, adanya harapan tinggi guru terhadap siswa, adanya ketertiban dan disiplin, fokus pada kegiatan yang berpusat pada siswa, serta adanya pengawasan pada pekerjaan (Hallinger \& Heck, 2011).

Berdasarkan Indeks Mutu Baik Sekolah di Indonesia yang dikeluarkan oleh Kementerian Pendidikan dan Kebudayaan, jenjang pendidikan SMK memiliki indeks mutu baik paling rendah dibandingkan dengan jenjang pendidikan lainnya yaitu hanya sebesar 12 persen SMK yang memiliki indeks mutu baik. Pengembangan bidang keahlian di lembaga pendidikan dan pelatihan vokasi pun dinilai belum sejalan dengan kebutuhan industri dan belum merespon kebutuhan pasar. Hal ini terlihat dari masih tingginya lulusan SMK yang belum bekerja ataupun terserap di dunia industri sebagaimana dipublikasikan oleh BPS pada Februari 2017 hingga 2019 (BPS, 2020). Hal ini terlihat dari tingginya tingkat pengangguran lulusan SMK selama tiga tahun terakhir, jenjang pendidikan SMK memiliki persentase pengangguran terbuka paling tinggi diatas tingkatan jenjang pendidikan lainnya yaitu berturut-turut sebesar 9.27 persen, 8.92 persen, dan 8.63 persen. Hal yang sama ditunjukkan pula oleh nilai akreditasi sekolah yang telah dikeluarkan oleh Badan Akreditasi Nasional yang menunjukkan bahwa SMK yang tersebar di Indonesia berada pada peringkat baik (Akreditasi B) dengan persentase sebesar 27.53 persen dan hanya 21.89 persen SMK dengan penilaian sangat baik (akreditasi A). Jumlah SMK yang bermutu baik cukup kecil, keterserapan yang rendah serta sedikitnya SMK yang bermutu. Hal ini menunjukkan bahwa perlu adanya strategi yang khusus melalui penelitian deduktif pada tataran persekolahan sebagai pusat keunggulan untuk meningkatkan efektivitas sekolah dan meningkatkan mutu layanan pendidikan di sekolah.

Disamping masalah mutu, pendidikan di Indonesia juga dihadapkan dengan adanya transformasi pelimpahan wewenang kepada daerah untuk mengurus kepentingan masyarakat berdasarkan aspirasi masyarakat sebagaimana dijelaskan pada Undangundang Nomor 23 tahun 2014 tentang Pemerintah Daerah. Selain itu, pemerintah provinsi sebagai penanggungjawab pendidikan SMK juga didorong untuk mengubah status SMK Negeri menjadi bentuk Badan Layanan Umum Daerah (BLUD) seperti tercantum dalam Peraturan Menteri Dalam Negeri Nomor 79 Tahun 2018 mengenai Badan Layanan Umum Daerah. Pada pelaksanaan operasional Sistem BLUD, sekolah mendapat hak prerogatif dalam mengimplementasikan praktik bisnis yang efektif dengan mengefisiensi anggaran yang ada, mengembangkan seluruh potensi yang dimiliki sesuai dengan bidang keahlian sekolah, serta menjadi jalan bagi siswa untuk terus berkarya.

Mengatasi permasalahan tersebut, diperlukan penerapan secara maksimal manajemen mutu terpadu atau Total Quality Managemet (TQM) di sekolah. Menurut Sallis (2010), dalam konteks pendidikan TQM merupakan sebuah filosofi metodologi tentang perbaikan secara berkesinambungan yang dapat memberikan seperangkat alat praktis kepada setiap institusi pendidikan dalam memenuhi kebutuhan, keinginan, dan harapan pelanggan, saat ini maupun masa yang akan datang. TQM meningkatkan organisasi pendidikan dalam berbagai hal, seperti meningkatkan proses pendidikan, membuat lingkungan pendidikan menjadi motivasi, meningkatkan kurikulum pendidikan, meningkatkan kecepatan layanan pelatihan dan mengurangi biaya (Peak, 1995) serta memiliki hubungan yang signifikan dengan efektivitas sekolah (Lezotte, 1992). TQM sendiri merupakan variabel yang disusun oleh beberapa dimensi variabel. Beberapa dimensi variabel penyusun TQM antara lain fokus pada pelanggan, fokus pada proses, dan perbaikan berkelanjutan (Bergman \& Klefsjö, 1994; Kanji et al., 1999; Kennerfalk, 1995).

Penelitian terkait TQM yang ada lebih mengeksplorasi seberapa dalam implemantasi TQM di sekolah seperti pada AlJammal \& Ghamrawi, 2013; Christine et al., 2017; Felestin \& Triyono, 2015b; Shahmohammadi, 2018; Soundararajan et al., 2018; Taşar \& Çelik, 2011; I. Wani \& Mehraj, 2014. Analisa pengaruh TQM lebih lanjut pun masih terbatas pada pengaruh TQM terhadap peningkatan mutu sekolah (Liantos \& Pamatmat, 2016; Svensson \& Klefsjö, 2006), kinerja siswa (Ruinge \& Kimani, 2015) dan tata kelola sekolah (Jaya et al., 2016). Penelitian terdahulu belum ada yang membahas secara detail terkait dengan pengaruh TQM terhadap efektivitas pengelolaan sekolah. Pemodelan yang menghubungkan TQM terhadap efektivitas pengelolaan sekolah, khususnya di SMK belum pernah diajukan sebelumnya. Penelitian terdahulu biasanya hanya membahas implementasi TQM terhadap kepemimpinan dan peningkatan kinerja sekolah seperti pada Liantos \& Pamatmat (2016) serta Bandur \& Gamage (2014) masih jarang yang memodelkan implementasi TQM terhadap efektivitas pengelolaan sekolah.

Selain TQM yang menjadi perhatian dalam penelitian ini yaitu variabel Kemandirian Sekolah Badan Pengawasan Keuangan dan Pembangunan (BPKP) yang merupakan tim pengembangan tata kelola pemerintahan yang baik di Indonesia memberikan acuan sebagai pengembangan, penerapan dan evaluasi dalam melaksanakan tata kelola yang baik yaitu salah satunya adalah kemandirian (BPKP, 2016). Kemandirian dalam hal ini berarti seorang kepala sekolah tidak terpengaruh dari tekanan oleh pihak lain yang tidak berkepentingan. Pada prinsip ini, kepala sekolah harus mampu mengelola sekolah secara tepat dan profesional tanpa desakan dari pihak lain yang terkait serta berlandaskan dengan peraturan dan perundang-undangan yang berlaku. Beberapa indikator yang digunakan dalam mengukur kemandirian sekolah antara lain pendelagasian tugas dilakukan secara jelas, adanya otonomi dalam melaksanakan kegiatan, dan kepala sekolah mendukung kegiatan sekolah.

Apabila dilihat dari pendekatan metode yang digunakan, penelitian yang biasanya hanya terfokus pada penelitian menggunakan pendekatan kuantitatif berupa analisis statistika dasar, seperti yang dilakukan (Abdul-Razak et al., 2014; Arar \& Nasra, 2018; Liantos \& Pamatmat, 2016; Panigrahi, 2014) dan analisis kualitatif seperti dilakukan oleh Alobiedat (2011); Bandur \& Gamage (2014); Svensson \& Klefsjö (2006). Penelitian efektivitas pengelolaan sekolah SMK-BLUD ini belum ada sebelumnya dan ditambah lagi digunakannya pendekatan kuantitatif berupa SEM PLS. 
Penelitian ini bertujuan untuk menganalisis faktor-faktor yang diduga berpengaruh terhadap efektivitas pengelolaan sekolah SMK-BLUD menggunakan SEM PLS. Efektivitas pengelolaan SMK-BLUD sebagai variabel dependen dan TQM yang meliputi fokus pada pelanggan, fokus pada proses, serta perbaikan berkelanjutan sebagai variabel independen. Disamping itu, penelitian ini juga mengikutkan variabel kemandirian sekolah sebagai variabel intervening untuk melihat apakah terdapat pengaruh secara tidak langsung antara fokus pada pelanggan, fokus pada proses, dan perbaikan berkelanjutan terhadap efektivitas pengelolaan sekolah SMK-BLUD. Harapannya, melalui penelitian diperoleh strategi peningkatan efektivitas dalam mengelola SMK-BLUD.

\section{METODE}

Penelitian ini merupakan penelitian kuantitatif dengan menggunakan Structural Equation Modelling (SEM). Teknik statistik SEM diperkenalkan oleh Wright, seorang ahli biometrik yang mengembangkan metode analisis jalur untuk memeriksa teori genetika dalam biologi (Teo \& Knine, 2009). Menurut Santoso (2018), SEM merupakan teknik analisis multivariat yang mengombinasikan antara analisis faktor dan analisis regresi linier dengan tujuan untuk menguji hubungan antar variabel pada suatu model. Metode ini dikembangkan dari metode regresi, ANOVA dan teknik korelasi dengan memungkinkan analisis interkoneksi hipotesis antara konstruk laten (Kline, 1991). SEM dapat menggambarkan pengaruh langsung maupun pengaruh tidak langsung dari variabel yang diamati berdasarkan pada hipotesis (Stage et al., 2004). Pengembangan SEM ditujukan untuk menjelaskan hubungan yang komplek antar variabel dan memungkinkan pengukuran dan model struktural antara variabel laten (sekelompok variabel eksogen). SEM sebagai salah satu analisis multivariat mampu melakukan pengujian secara simultan pada model penelitian yang bersifat rumit serta mampu melakukan analisis variabel yang tidak dapat dihitung secara langsung (Hair Jr et al., 2016).

Terdapat dua tipe SEM, yakni SEM yang berbasis kovarian dan SEM yang berbasis varian (SEM-PLS). SEM berbasis varian atau yang dikenal dengan Structural Equation Modeling-Partial Least Square (SEM-PLS) (Wold, 1975). SEM-PLS merupakan suatu analisis berbasis varian yang dapat melakukan pengujian model pengukuran dan struktural secara simultan (Hair Jr et al., 2016). SEM PLS digunakan pada penelitian yang bersifat eksploratori, artinya SEM bertujuan untuk mengembangkan teori serta menghasilkan prediksi dan penjelasan variabel laten. SEM juga dapat memaksimumkan varian dari variabel laten endogen yang dipengaruhi oleh variabel laten eksogen. Secara umum, pada metode SEM-PLS, terdapat dua bentuk model pengukuran yaitu reflektif dan formatif. Menurut Bollen \& Lennox (1991), konstruk untuk model reflektif atau formatif dipilih berdasarkan prioritas keterkaitan timbal balik antara indikator dengan variabel laten. Pada hubungan reflektif, indikator merupakan cerminan dari variabel latennya sementara perubahan variabel laten yang diakibatkan oleh perubahan indikator hubungan formatif digambarkan oleh model indikator formatif. Pengujian hubungan antar variabel tersebut dapat terjadi antara indikator dengan konstruknya ataupun hubungan antar konstruk. Menurut Ghazali \& Latan (2015), PLS merupakan pendekatan untuk estimasi paramater sebagai alternatif dari pendekatan SEM berbasis kovarian menjadi berbasis varian. Analisis dalam penelitian ini menggunakan pendekatan SEM-PLS yang dilakukan dengan dua tahap.

\section{Uji Measurement Model}

Pada tahap ini dilakukan untuk menguji validitas dan reliabilitas konstruk dari masing-masing indikator. Penelitian ini menggunakan kuesioner dalam mengumpulkan data penelitian. Untuk mengetahui tingkat validitas dan reliabilitas dari kuesioner tersebut maka peneliti menggunakan softaware Smart PLS 3.0. Prosedur pengujian validitas adalah convergent validity yaitu dengan mengorelasikan butir skor (component score) dengan construct score yang kemudian menghasilkan nilai Loading Factor. Nilai Loading Factor dikatakan tinggi jika komponen atau indikator berkorelasi lebih dari 0.7 dengan konstruk yang ingin diukur. Namun demikian, untuk penelitian tahap awal dari pengembangan, Loading Factor 0.5 sampai 0.6 dianggap cukup (Chin, 1998; Ghozali \& Fuad, 2008).

Reliabilitas menyatakan sejauh mana hasil atau pengukuran dapat dipercaya atau dapat diandalkan dan memberikan hasil pengukuran yang cenderung konsisten setelah dilakukan pengukuran berulang. Untuk mengukur tingkat reliabilitas variabel digunakan koefisien Cronbach Alpha dan Composite Reliability. Variabel pengukuran dikatakan reliabel jika memiliki nilai koefisien Alfa lebih besar dari 0.6 (Malhotra \& Dash, 2016).

\section{Uji Struktural Model}

Tujuan pada tahap ini adalah untuk mengetahui ada tidaknya pengaruh antar variabel antara konstruk-konstruk yang diukur dengan menggunakan pendekatan uji-t dari model PLS itu sendiri. Selain itu, uji struktural model digunakan untuk melihat hubungan antara konstruk yang diukur yang merupakan Uji-t dari Partial Least Square itu sendiri. Struktural model dapat diukur dengan melihat nilai koefisien estimasi dari model yang menunjukkan seberapa besar pengaruh antar variabel dalam model. Kemudian langkah selanjutnya adalah estimasi koefisien jalur yang merupakan nilai estimasi untuk hubungan jalur dalam model struktural yang diperoleh dengan prosedur stripping dengan nilai yang dianggap signifikan Jika nilai T-statistik lebih besar dari 1.96 (tingkat signifikansi 5\%) atau lebih besar dari 1.65 (tingkat signifikansi 10\%) untuk masing-masing hubungan jalurnya. 
Pendektaan dengan PLS merupakan metode analisis statistik yang powerful karena tidak didasarkan pada banyak asumsi (Wold, 1975). Data yang digunakan dalam analisis tidak harus terdistribusi normal multivariat dan jumlah sampel responden tidak harus besar. PLS dapat digunakan untuk mengonfirmasi teori yang sudah ada dan untuk menjelaskan ada tidaknya pengaruh antara variabel laten. PLS dapat juga untuk menganalisis sekaligus konstruk-konstruk yang dibentuk dengan indikator reflektif ataupun indikator formatif dimana hal seperti ini tidak dapat dijalankan dalam Covariance Based SEM. Hal ini dikarenakan akan terjadi unidentified model pada pemodelan Covariance Based SEM (Ghazali \& Latan, 2015). Pada penelitian ini, terdapat enam hipotesis yang diajukan, yakni (1) $\mathrm{H}_{1}$ : terdapat pengaruh yang positif dan signifikan fokus pada pelanggan terhadap efektivitas sekolah; (2) $\mathrm{H}_{2}$ : terdapat pengaruh yang positif dan signifikan fokus pada proses terhadap efektivitas sekolah; (3) $\mathrm{H}_{3}$ : terdapat pengaruh yang positif dan signifikan perbaikan berkelanjutan terhadap efektivitas sekolah; (4) $\mathrm{H}_{4}$ : terdapat pengaruh yang positif dan signifikan antara fokus pada pelanggan terhadap efektivitas sekolah melalui kemandirian; (5) $\mathrm{H}_{5}$ : terdapat pengaruh yang positif dan signifikan antara fokus pada proses terhadap efektivitas sekolah melalui kemandirian; (6) $\mathrm{H}_{6}$ : terdapat pengaruh yang positif dan signifikan antara perbaikan berkelanjutan terhadap efektivitas sekolah melalui kemandirian.

\section{HASIL}

Total responden pada penelitian ini sebanyak 231 orang yang berasal dari provinsi Jawa Timur dan DKI Jakarta. Pengambilan sampel dilakukan di dua provinsi tersebut dikarenakan hanya kedua provinsi tersebut yang memiliki SMK-BLUD. Responden yang paling banyak berasal dari provinsi Jawa Timur yaitu sebesar 84\% atau sebanyak 195 orang, sedangkan responden yang berasal dari DKI Jakarta hanya sebesar $16 \%$ atau sebanyak 36 orang. DKI Jakarta. Besarnya proporsi responden yang berasal dari Jawa Timur ini sejalan dengan banyaknya jumlah SMK-BLUD yang ada di provinsi tersebut. SMK-BLUD yang ada di Jawa Timur empat kali lebih banyak apabila dibandingkan dengan SMK yang berstatus BLUD di DKI Jakarta. Sebanyak 20 SMK-BLUD berada di provinsi Jawa Timur, sementara lima SMK_BLUD lainnya terletak di DKI Jakarta.

Jawa Timur,

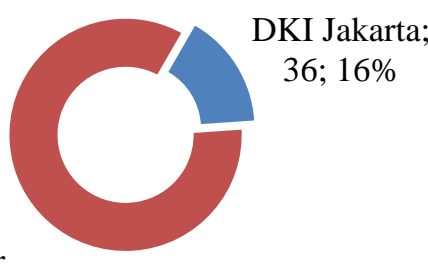

- DKI Jakarta - Jawa Timur

Gambar 1. Grafik Jumlah Responden

Tabel 1. Hasil Perbandingan Rata-Rata Berdasarkan Lokasi Responden

\begin{tabular}{llcccc}
\hline \multicolumn{1}{c}{ Variabel } & Lokasi Responden & N & Mean & Std.Dev & p-value \\
\hline Perbaikan Berkelanjutan & DKI Jakarta & 36 & 3.5764 & 0.64315 & 0.837 \\
& Jawa Timur & 195 & 3.5962 & 0.50518 & \\
\hline Fokus pada pelanggan & DKI Jakarta & 36 & 3.4514 & 0.65143 & 0.673 \\
& Jawa Timur & 195 & 3.5000 & 0.50064 & \\
\hline Fokus pada proses & DKI Jakarta & 36 & 3.5186 & 0.64488 & 0.592 \\
& Jawa Timur & 195 & 3.5796 & 0.48941 & \\
\hline Kemandirian & DKI Jakarta & 36 & 3.5000 & 0.69693 & 0.42 \\
& Jawa Timur & 195 & 3.6000 & 0.55982 & \\
\hline Efektivitas Sekolah & DKI Jakarta & 36 & 3.5489 & 0.18709 & $0.044 * *$ \\
& Jawa Timur & 195 & 3.6169 & 0.13939 & \\
\hline
\end{tabular}

Keterangan: $* *=$ signifikan pada taraf $5 \%, *$ signifikan pada taraf $10 \%$

Pada tabel 1 memperlihatkan hasil uji Independen t-test pada masing-masing variabel berdasarkan lokasi responden. Pada variabel Perbaikan Berkelanjutan, Fokus pada pelanggan, dan Kemandirian memiliki nilai p-value $>0.05$. Artinya pada variabel-variabel tersebut tidak memberikan perbedaan yang signifikan antara responden yang berasal dari SMK di Provinsi DKI Jakarta dan Jawa Timur, sedangkan pada variabel Efektivitas Sekolah memiliki nilai p-value < 0.05. Artinya, SMK di Provinsi DKI Jakarta dan Jawa Timur mempunyai efektivitas sekolah yang berbeda secara siginfikan pada taraf signifikansi $5 \%$. 


\section{Uji Validitas dan Realibilitas}

Pada gambar 2 dapat dilihat bahwa nilai Standardized loading factor setiap indikator lebih besar dari 0.7. Artinya indikator-indikator pada model tersebut telah valid sebagai alat ukur untuk variabel latennya sehingga dapat digunakan untuk pemodelan.

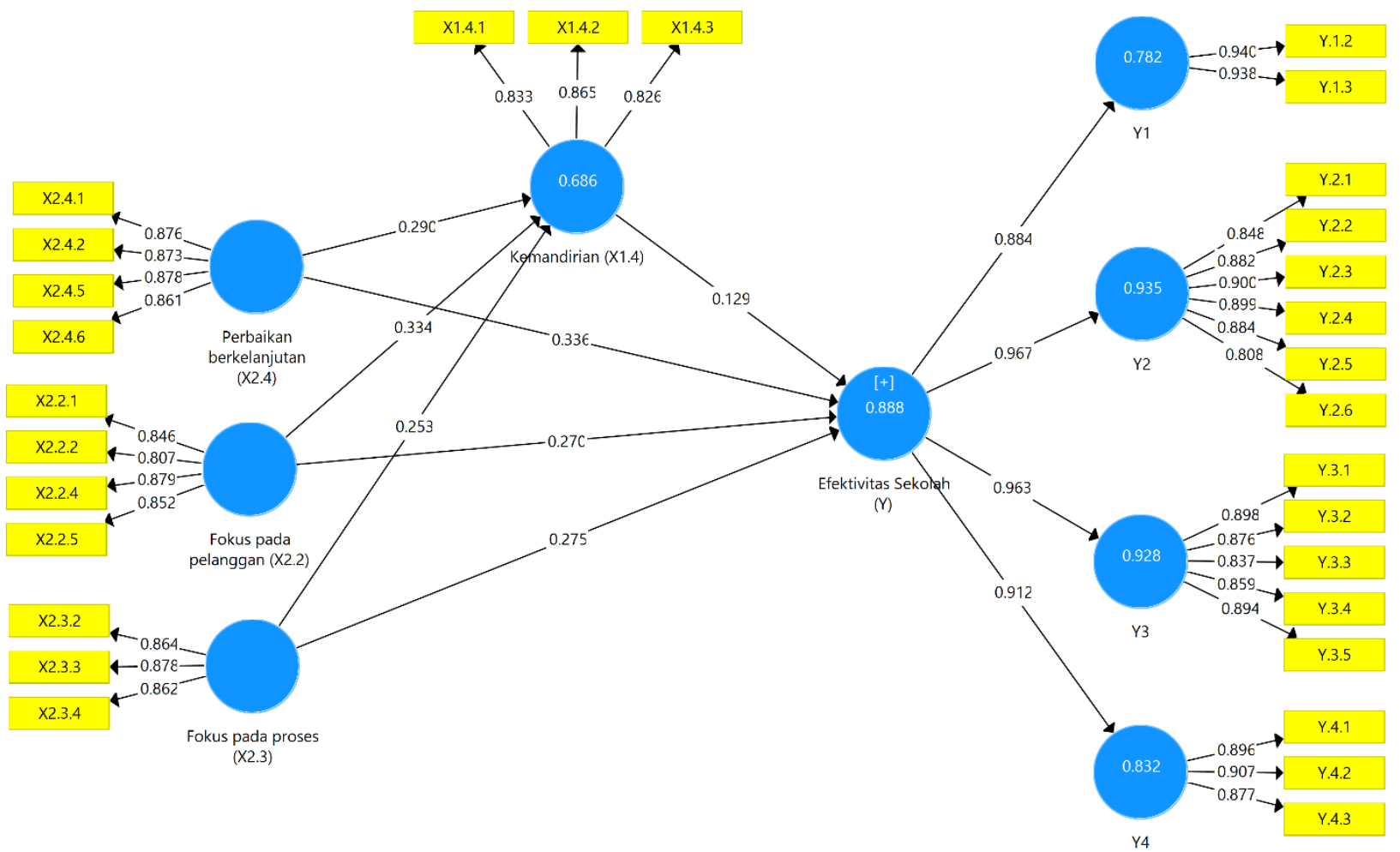

Gambar 2. Model Struktural dengan Nilai Standardized Loading Factor

Tabel 2. Nilai Cronbach's Alpha

\begin{tabular}{lc}
\hline \multicolumn{1}{c}{ Variabel } & Cronbach's Alpha \\
\hline Efektivitas Sekolah (Y) & 0.971 \\
Fokus pada pelanggan (X2.2) & 0.868 \\
Fokus pada proses (X2.3) & 0.836 \\
Kemandirian (X1.4) & 0.794 \\
Perbaikan berkelanjutan (X2.4) & 0.895 \\
Y1 & 0.866 \\
Y2 & 0.936 \\
Y3 & 0.922 \\
Y4 & 0.873 \\
\hline
\end{tabular}

Berdasarkan tabel 2 diperoleh nilai koefisien Cronbach Alpha pada semua variabel $\geq 0,60$. Sehingga dapat disimpulkan bahwa semua variabel laten dinyatakan telah reliabel. 


\section{Evaluasi Outer Model}

Tabel 3. Nilai Composite Reliability

\begin{tabular}{lc}
\hline \multicolumn{1}{c}{ Variabel } & Composite Reliability \\
\hline Efektivitas Sekolah (Y) & 0.974 \\
Fokus pada pelanggan (X2.2) & 0.910 \\
Fokus pada proses (X2.3) & 0.902 \\
Kemandirian (X1.4) & 0.879 \\
Perbaikan berkelanjutan (X2.4) & 0.927 \\
Y1 & 0.937 \\
Y2 & 0.949 \\
Y3 & 0.941 \\
Y4 & 0.922 \\
\hline
\end{tabular}

Nilai pada semua blok indikator lebih besar 0,6 maka telah memenuhi asumsi Composite Reliability. Tabel 3 menunjukkan bahwa blok indikator pada masing-masing konstruk memiliki konsistensi yang tinggi.

Tabel 4. Cross-Loading

\begin{tabular}{|c|c|c|c|c|c|c|c|c|}
\hline & $\begin{array}{l}\text { Fokus pada } \\
\text { pelanggan }(\mathrm{X} 2.2)\end{array}$ & $\begin{array}{l}\text { Fokus pada } \\
\text { proses (X2.3) }\end{array}$ & $\begin{array}{l}\text { Kemandirian } \\
\text { (X1.4) }\end{array}$ & $\begin{array}{l}\text { Perbaikan } \\
\text { berkelanjutan (X2.4) }\end{array}$ & Y1 & Y2 & Y3 & Y4 \\
\hline $\mathrm{X} 1.4 .1$ & 0.672 & 0.656 & $\mathbf{0 . 8 3 3}$ & 0.667 & 0.607 & 0.666 & 0.655 & 0.652 \\
\hline $\mathrm{X} 1.4 .2$ & 0.675 & 0.674 & 0.865 & 0.664 & 0.614 & 0.674 & 0.682 & 0.612 \\
\hline X1.4.3 & 0.643 & 0.634 & 0.826 & 0.642 & 0.592 & 0.673 & 0.629 & 0.639 \\
\hline $\mathrm{X} 2.2 .1$ & 0.846 & 0.725 & 0.642 & 0.686 & 0.637 & 0.724 & 0.730 & 0.644 \\
\hline $\mathrm{X} 2.2 .2$ & 0.807 & 0.675 & 0.608 & 0.659 & 0.555 & 0.770 & 0.672 & 0.580 \\
\hline $\mathrm{X} 2.2 .4$ & 0.879 & 0.758 & 0.754 & 0.758 & 0.707 & 0.740 & 0.771 & 0.726 \\
\hline $\mathrm{X} 2.2 .5$ & 0.852 & 0.688 & 0.656 & 0.718 & 0.669 & 0.714 & 0.716 & 0.700 \\
\hline $\mathrm{X} 2.3 .2$ & 0.715 & 0.864 & 0.689 & 0.730 & 0.670 & 0.740 & 0.771 & 0.706 \\
\hline $\mathrm{X} 2.3 .3$ & 0.795 & 0.878 & 0.679 & 0.766 & 0.666 & 0.763 & 0.747 & 0.729 \\
\hline $\mathrm{X} 2.3 .4$ & 0.679 & 0.862 & 0.659 & 0.701 & 0.629 & 0.749 & 0.713 & 0.666 \\
\hline $\mathrm{X} 2.4 .1$ & 0.778 & 0.786 & 0.711 & 0.876 & 0.674 & 0.753 & 0.787 & 0.740 \\
\hline $\mathrm{X} 2.4 .2$ & 0.696 & 0.738 & 0.670 & 0.873 & 0.732 & 0.730 & 0.765 & 0.796 \\
\hline $\mathrm{X} 2.4 .5$ & 0.737 & 0.752 & 0.695 & 0.878 & 0.656 & 0.766 & 0.750 & 0.704 \\
\hline $\mathrm{X} 2.4 .6$ & 0.697 & 0.666 & 0.650 & 0.861 & 0.678 & 0.726 & 0.704 & 0.687 \\
\hline Y.1.2 & 0.734 & 0.698 & 0.677 & 0.712 & 0.940 & 0.770 & 0.770 & 0.753 \\
\hline Y.1.3 & 0.694 & 0.719 & 0.672 & 0.763 & 0.938 & 0.755 & 0.766 & 0.729 \\
\hline Y.2.1 & 0.774 & 0.730 & 0.700 & 0.785 & 0.736 & 0.848 & 0.761 & 0.733 \\
\hline Y.2.2 & 0.764 & 0.791 & 0.713 & 0.754 & 0.746 & 0.882 & 0.811 & 0.754 \\
\hline Y.2.3 & 0.787 & 0.778 & 0.700 & 0.760 & 0.718 & 0.900 & 0.783 & 0.716 \\
\hline Y.2.4 & 0.766 & 0.745 & 0.704 & 0.741 & 0.673 & 0.899 & 0.770 & 0.701 \\
\hline Y.2.5 & 0.770 & 0.762 & 0.674 & 0.700 & 0.669 & 0.884 & 0.812 & 0.695 \\
\hline Y.2.6 & 0.678 & 0.710 & 0.674 & 0.716 & 0.699 & 0.808 & 0.772 & 0.752 \\
\hline Y.3.1 & 0.722 & 0.768 & 0.695 & 0.749 & 0.736 & 0.776 & 0.898 & 0.744 \\
\hline Y.3.2 & 0.719 & 0.763 & 0.671 & 0.799 & 0.680 & 0.744 & 0.876 & 0.750 \\
\hline Y.3.3 & 0.733 & 0.706 & 0.661 & 0.708 & 0.646 & 0.816 & 0.837 & 0.648 \\
\hline Y.3.4 & 0.737 & 0.711 & 0.704 & 0.739 & 0.746 & 0.761 & 0.859 & 0.778 \\
\hline Y.3.5 & 0.815 & 0.792 & 0.671 & 0.770 & 0.758 & 0.839 & 0.894 & 0.749 \\
\hline Y.4.1 & 0.710 & 0.731 & 0.664 & 0.766 & 0.761 & 0.753 & 0.780 & 0.896 \\
\hline Y.4.2 & 0.712 & 0.740 & 0.666 & 0.782 & 0.720 & 0.758 & 0.783 & 0.907 \\
\hline Y.4.3 & 0.682 & 0.691 & 0.691 & 0.698 & 0.630 & 0.721 & 0.686 & 0.877 \\
\hline
\end{tabular}


Validitas diskriminan indikator dapat dilihat pada cross-loading antara indikator dengan konstruknya. Dari tabel 4 terlihat bahwa korelasi konstruk fokus pada pelanggan (X2.2) dengan indikatornya lebih tinggi dibanding dengan konstruk lainnya. Hal itu berlaku juga untuk konstruk Fokus pada proses (X2.3), Kemandirian (X1.4), Y1, Y2, Y3, dan Y4 dengan masing-masing indikatornya. Hal ini menunjukan bahwa konstruk laten dapat memprediksi indikator pada blok dirinya sendiri lebih baik dibanding konstruk lainnya.

\section{Evaluasi Model Struktural}

Berdasarkan hasil analisis dengan menggunakan software Smart PLS diperoleh nilai $R^{2} 0.888$ dan 0.686. Hal ini menunjukkan bahwa variabel Efektivitas Sekolah (Y) dapat dijelaskan dengan baik oleh variabel Kemandirian (X1.4), Perbaikan Berkelanjutan (X2.4), Fokus pada Pelanggan (X2.2), dan Fokus pada Proses (X2.3) sebesar 88.8\% sedangkan sebesar 11.2\% dijelaskan oleh variabel lain yang diluar yang diteliti. Sedangkan variabel Kemandirian (X1.4) dapat dijelaskan oleh Perbaikan Berkelanjutan (X2.4), Fokus pada Pelanggan (X2.2), dan Fokus pada Proses (X2.3) sebesar 68.6\% sedangkan sebesar 31.4\% dijelaskan oleh variabel lain yang diluar yang diteliti.

Tabel 5. Nilai $R^{2}$ pada model Struktural

\begin{tabular}{lr}
\hline Variabel & R Square \\
\hline Efektivitas Sekolah (Y) & 0.888 \\
Kemandirian (X1.4) & 0.686 \\
\hline
\end{tabular}

Nilai $Q^{2}$ digunakan untuk memvalidasi model. Apabila nilai $\mathrm{Q}^{2}$ lebih besar dari 0.5 menunjukkan bahwa model memiliki Predictive Relevance yang baik. Nilai Predictive Relevance $\left(\mathrm{Q}^{2}\right)$ dapat dituliskan sebagai sebagai berikut:

$Q_{2}=1-\left\{\left(1-R_{1}\right)\left(1-R_{2}\right)\right\}$

$=1-\{(1-0.888)(1-0.686)\}=0.965$

Dari perhitungan di atas diperoleh nilai $\mathrm{Q}^{2}=0.965$ lebih besar dari 0.5 , artinya model dalam penelitian ini memiliki Predictive Relevance yang baik.

\section{Pengujian Hipotesis}

PLS tidak mengasumsikan bahwa data berdistribusi normal maka digunakan teknik resampling dengan metode Bootstrapping. Hasil dari bootstrapping dengan sampel bootstrap sebanyak 500 kali diasumsikan data telah berdistribusi normal sehingga pengujian parameter dalam model dapat dilakukan dengan uji t. Nilai koefisien dari model struktural dikatakan signifikan jika nilai t-hitung > t-tabel yakni sebesar 1,96 (1,96 adalah nilai t-tabel dengan $\mathrm{db}=\mathrm{n}-1$ dalam tingkat kepercayaan $95 \%)$ atau nilai $\mathrm{p}<\alpha(0.05)$.

Tabel 6. Hasil Pengaruh Langsung (Direct Effect)

\begin{tabular}{lllll}
\hline Pengaruh Variabel & $\begin{array}{l}\text { Estimasi } \\
\text { Koefisien }\end{array}$ & $\begin{array}{l}\text { Standard } \\
\text { Deviation }\end{array}$ & t-Statistics & P-Values \\
\hline Fokus pada pelanggan (X2.2) -> Efektivitas Sekolah (Y) & 0.270 & 0.063 & 4.298 & $0.000^{* *}$ \\
Fokus pada proses (X2.3) -> Efektivitas Sekolah (Y) & 0.275 & 0.068 & 4.067 & $0.000^{* *}$ \\
Perbaikan berkelanjutan (X2.4) -> Efektivitas Sekolah (Y) & 0.336 & 0.061 & 5.498 & $0.000^{* *}$ \\
\hline
\end{tabular}

Keterangan: **: Signifikan pada taraf 5\%

Berdasarkan tabel 6 diketahui bahwa koefisien jalur pada variabel laten fokus pada pelanggan terhadap efektivitas sekolah bernilai sebesar 0.270 dengan t-hitung sebesar 4.298 dan nilai p sebesar 0.000 . Artinya, $\mathrm{H}_{1}$ diterima yang bermakna terdapat pengaruh yang positif dan signifikan antara fokus pada pelanggan terhadap efektivitas sekolah. Hal ini menandakan bahwa semakin baik penerapan fokus pada pelanggan di sekolah maka akan semakin baik pula efektivitas di sekolah tersebut, begitu pula sebalikannya. Pengaruh positif dan signifikan antara fokus pada pelanggan terhadap efektivitas sekolah, khsushnya pada SMK, sejalan dengan penelitian yang dilakukan oleh Shahmohammadi (2018). Menurut (Soghati, 2012), salah satu cara bagi institusi pendidikan khususnya sekolah untuk membedakan pelayanannya dengan organisasi lain adalah dengan terus menerus menyediakan program-program yang berkualitas agar siswa terlibat dalam meningkatkan keterampilan dan proses pembelajaran secara terus menerus, mendorong siswa untuk bertanggung jawab atas pembelajaran, dan mempromosikan kemampuan mereka di semua tingkat pembelajaran berdasarkan tujuan konkret.

Hipotesis kedua, yakni terdapat pengaruh yang positif dan signifikan fokus pada proses terhadap efektivitas sekolah dibuktikan dengan nilai koefisien sebesar 0.275 dan nilai p sebesar $0.000(\mathrm{p}<0.005)$. Artinya $\mathrm{H}_{2}$ diterima yang bermakna bahwa semakin baik penerapan fokus pada proses di SMK-BLUD maka akan semakin baik pula efektivitas pengelolaan sekolah tersebut, 
begitu pula sebaliknya. Fokus pada proses artinya sekolah berusaha untuk mengajak siswa, orangtua, dan staf menjadi pemikir yang aktif, otomatis, efektif, dan kritis, agar layanan sekolah dapat memenuhi kebutuhan masyarakat (Nejad, 2014).

Hipotesis ketiga yakni terdapat pengaruh yang positif dan signifikan perbaikan berkelanjutan terhadap efektivitas sekolah dibuktikan dengan nilai koefisien sebesar 0.336 dan nilai $\mathrm{p}$ sebesar $0.000(\mathrm{p}<0.005)$. Artinya $\mathrm{H}_{3}$ diterima yang bermakna bahwa semakin baik perbaikan berkelanjutan di terapkan di SMK-BLUD maka akan semakin baik pula efektivitas pengelolaan sekolah tersebut, begitu pula sebaliknya. Menurut Carpenter (2015), perbaikan berkelanjutan difokuskan pada peningkatan pengajaran dan pembelajaran untuk memastikan semua siswa berprestasi di tingkat tinggi dengan merefleksikan pengajaran dan pembelajaran sebelumnya, mengembangkan strategi dan praktik inovatif untuk memastikan semua siswa dapat mencapai dan menerapkan inovasi, menganalisis dampak inovasi, dan menerapkan pengetahuan baru yang diperoleh dari siklus perbaikan berkelanjutan ke siklus berikutnya. Selain pengaruh langsung, penelitian ini juga memiliki pengaruh tidak langsung yang menjadi kebaruan dalam pengembangan model. Pengaruh tidak langsung pada penelitian ini dijelaskan pada tabel 7.

Tabel 7. Hasil Pengaruh Tidak Langsung (Indirect Effect)

\begin{tabular}{|c|c|c|c|c|}
\hline Pengaruh Variabel & Estimasi Koefisien & Standard Deviation & t-Statistics & P-Values \\
\hline $\begin{array}{l}\text { Fokus pada pelanggan (X2.2) -> Kemandirian } \\
(\mathrm{X} 1.4)->\text { Efektivitas Sekolah (Y) }\end{array}$ & 0.043 & 0.020 & 2.177 & $0.030 * *$ \\
\hline $\begin{array}{l}\text { Fokus pada proses (X2.3)-> Kemandirian } \\
(\mathrm{X} 1.4)->\text { Efektivitas Sekolah (Y) }\end{array}$ & 0.033 & 0.018 & 1.816 & 0.070 \\
\hline $\begin{array}{l}\text { Perbaikan berkelanjutan (X2.4) -> Kemandirian } \\
\text { (X1.4) -> Efektivitas Sekolah (Y) }\end{array}$ & 0.037 & 0.017 & 2.192 & $0.029 * *$ \\
\hline
\end{tabular}

Keterangan: **: Signifikan pada taraf 5\%*

Berdasarkan tabel 7 diperoleh bahwa terdapat pengaruh yang positif dan signifikan fokus pada pelanggan terhadap efektivitas sekolah melalui variabel kemandirian. Hal ini dibuktikan dengan nilai p sebesar $0.030(\mathrm{p}<0.005)$. Artinya, $\mathrm{H}_{4}$ diterima yang bermakna bahwa semakin baik penerapan fokus pada pelanggan di sekolah maka akan semakin baik pula kemandirian di sekolah tersebut yang pada akhirnya memiliki pengaruh yang positif dan signifikan terhadap peningkatan efektivitas sekolah. Hasil koefisien estimasi pada pengaruh tidak langsung ini sebesar 0.043 yang lebih kecil dari koefisien estimasi antara pada pengaruh langsung antara fokus pada pelanggan terhadap efektivitas sekolah (0.27) yang menandakan bahwa hubungan sebenarnya antara fokus pada pelanggan terhadap efektivitas sekolah merupakan hubungan yang langsung.

Hasil pengujian hipotesis kelima menunjukkan bahwa koefisien jalur pada variabel laten fokus pada proses terhadap efektivitas sekolah melalui kemandirian bernilai sebesar 0.033 dengan t-hitung sebesar 1.816 dan nilai $\mathrm{p}$ sebesar 0.070 ( $\mathrm{p}>0.05$ ). Hal ini menjelaskan bahwa variabel laten fokus pada proses tidak berpengaruh secara positif dan signifikan terhadap variabel laten efektivitas sekolah melalui variabel kepemimpinan. Artinya, variabel kepemimpinan tidak terbukti secara statistik dapat menjadi perantara antara variabel fokus pada proses dan efektivitas sekolah.

Hasil pengujian hipotesis keenam menunjukkan bahwa terdapat pengaruh yang positif dan signifikan pada variabel laten perbaikan berkelanjutan terhadap efektivitas sekolah melalui kemandirian. Hal ini dibuktikan dengan nilai $p$ sebesar 0.030 yang lebih besar dari 0.05. Artinya, $\mathrm{H}_{6}$ diterima yang bermakna bahwa semakin baik penerapan fokus pada proses di sekolah maka akan semakin baik pula kemandirian di sekolah tersebut yang pada akhirnya memiliki pengaruh yang positif dan signifikan terhadap peningkatan efektivitas sekolah. Hasil koefisien estimasi pada pengaruh tidak langsung ini sebesar 0.037 yang lebih kecil dari koefisien estimasi pada pengaruh langsung antara fokus pada proses terhadap efektivitas sekolah (0.336) yang menandakan bahwa hubungan sebenarnya antara fokus pada proses terhadap efektivitas sekolah merupakan hubungan yang langsung.

\section{PEMBAHASAN}

Hasil pengujian hipotesis seperti yang disajikan pada tabel 6 dapat diinterpretasikan sebagai berikut. Pertama, variabel fokus pada pelanggan (X2.2) berpengaruh signifikan terhadap efektivitas sekolah (Y) pada taraf signifikansi 5\% dengan nilai koefisien estimasi bernilai positif yaitu sebesar 0.270. Dapat disimpulkan bahwa setiap peningkatan Fokus pada pelanggan pada setiap sekolah maka akan meningkatkan efektivitas pengelolaan sekolah SMK-BLUD. Kedua, variabel fokus pada proses (X2.3) berpengaruh signifikan terhadap efektivitas sekolah (Y) pada taraf signifikansi 5\% dengan nilai koefisien estimasi bernilai positif yaitu sebesar 0.275. Dapat disimpulkan bahwa setiap peningkatan fokus pada proses di setiap sekolah maka akan meningkatkan efektivitas pengelolaan sekolah SMK-BLUD. Ketiga, variabel perbaikan berkelanjutan (X2.4) berpengaruh signifikan terhadap efektivitas sekolah (Y) pada taraf signifikansi 5\% dengan nilai koefisien estimasi bernilai positif yaitu sebesar 0.336. Dapat disimpulkan bahwa setiap peningkatan perbaikan berkelanjutan pada setiap sekolah maka akan meningkatkan efektivitas pengelolaan sekolah SMK-BLUD. Kesimpulan hasil pada tabel 6 yaitu TQM, meliputi variabel fokus pada pelanggan, fokus pada proses, dan perbaikan berkelanjutan memiliki pengaruh signifikan terhadap efektivitas sekolah. Hal ini sejalan dengan penelitian 
Liantos \& Pamatmat (2016) yang menyiratkan bahwa TQM memiliki pengaruh terhadap peningkatan kinerja sekolah. Selain itu, pada (Khurniawan, Sailah, Muliono, et al., 2020) menyebutkan bahwa TQM berpengaruh positif dan signifikan terhadap peningkatan efektivitas pengelolaan SMK.

Selanjutnya hasil pengujian hipotesis pada tabel 7 dapat dijelaskan bahwa variabel kemandirian (X1.4) signifikan memediasi hubungan antara fokus pada pelanggan (X2.2) dan perbaikan berkelanjutan (X2.4) terhadap efektivitas sekolah (Y) pada taraf signifikansi 5\%. Selain itu, variabel kemandirian (X1.4) juga signifikan memediasi hubungan antara fokus pada proses (X2.3) terhadap efektivitas sekolah (Y) pada taraf signifikansi 10\%. Hal ini dapat disimpulkan bahwa setiap peningkatan fokus pada pelanggan, dan perbaikan berkelanjutan pada setiap sekolah maka akan meningkatkan efektivitas pengelolaan sekolah SMKBLUD melalui kemandirian sekolah. Hal ini sejalan dengan penelitian yang dilakukan oleh Fadila et al. (2020); Nurhafifah et al. (2016); Salim (2017) yang menyiratkan bahwa penguatan kemampuan manajerial kepala sekolah mampu meningkatkan efektivitas pengelolaan sekolah. Selain itu, kepemimpinan situasional dan budaya sekolah mempunyai pangaruh positif dan signifikan terhadap efektivitas sekolah.

\section{SIMPULAN}

Berdasarkan hasil analisa data dan pembahasan menggunakan pendekatan metode Partial Least Square (PLS) secara keseluruhan dapat disimpulkan bahwa hasil evaluasi dari model pengukuran menunjukkan semua indikator telah valid dan realibel dalam mengukur setiap variabel latennya sehingga dapat digunakan untuk membentuk variabel-variabel yang memengaruhi efektivitas sekolah SMK di Provinsi DKI Jakarta dan Jawa Timur. Berdasarkan hasil pengujian hipotesis menunjukkan bahwa variabel fokus pada pelanggan, fokus pada proses, dan perbaikan berkelanjutan memberikan pengaruh yang positif dan signifikan terhadap efektivitas sekolah. Selain itu, dengan adanya kemandirian pada setiap sekolah, secara tidak langsung juga memberikan pengaruh yang positif dan signifikan terhadap efektivitas sekolah.

Efektivitas pengelolaan sekolah perlu ditingkatkan secara maksimal dengan melihat kondisi pada masing-masing sekolah sehingga dapat menentukan strategi yang tepat dalam menentukan keefektifan sekolah. Selain menggunakan variabel kemandirian sebagai variabel intervening dalam meningkatkan efektivitas pengelolaan sekolah, diperlukan variabel intervening lain yang dapat memaksimalkan keefektifan sekolah dalam melakukan pengelolaan SMK-BLUD. Menurut Khurniawan, Sailah, Muljono, et al. (2020), penerapan TQM di Indonesia, khususnya di SMK perlu ditingkatkan dengan menyediakan infrastruktur yang canggih, tenaga pengajar yang berkualitas, dan manajemen yang berkualitas. Oleh karena itu, pada penelitian selanjutnya dapat ditambahkan variabel intervening terkait tenaga pengajar yang berkualitas dan manajemen yang berkualitas untuk meningkatkan evektivitas pengelolaan sekolah SMK-BLUD.

\section{DAFTAR RUJUKAN}

Badan Pusat Statistik. (2020). Laporan Bulanan Data Sosial Ekonomi (Subdirektorat Publikasi dan Kompilasi Statistik (ed.); $9^{\text {th }}$ ed.). Badan Pusat Statistik. http://www.bps.go.id

Abdul-razak, T., Bawa, Wumbie, M., \& Abdul-razak, A. (2014). Asssessment of the Effects of Total Quality Management on School Performance in the Chereponi Education Directorate. International Journal of Interdisciplinary and Multidisciplinary Studies., 1(5), 294-arie308.

Al-Jammal, K., \& Ghamrawi, N. (2013). Total quality management: Effectiveness in Lebanese Schools Perceptions of School Leaders and Teachers. International Journal of Management, 1(12), 488-509.

Alobiedat, A. (2011). The Effectiveness of the School Performance by Using the Total Quality Standards within the Education District of Al-Petra Province, from the Perspective of the Public Schools Principals and Teachers. International Education Studies., 4(2), 31-40. https://doi.org/10.5539/ies.v4n2p31

Arar, K., \& Nasra, M. A. (2018). Linking School-Based Management and School Effectiveness: The Influence of Self-Based Management, Motivation, and Effectiveness in the Arab Education System in Israel. Educational Management Administration \& Leadership, 48(1), 186-204. https://doi.org/10.1177/1741143218775428

Bandur, A., \& Gamage, D. T. (2014). How Did School Councils in Indonesia Improve Teaching/Learning Environments and Student Achievements? Journal of Applied Research in Education, 18, 15-28.

Bergman, B., \& Klefsjö, B. (1994). Quality from Customer Needs to Customer Satisfaction. London and Studentlitteratur Lund.

Bollen, K., \& Lennox, R. (1991). Conventional Wisdom on Measurement: A Structural Equation Perspective. Psychological Bulletin, 110(2), 305.

Carpenter, D. (2015). School Culture and Leadership of Professional Learning Communities. International Journal of Educational Management, 29(5), 682-694. https://doi.org/10.1108/IJEM-04-2014-0046

Chin, W. W. (1998). The Partial Least Squares Approach to Structural Equation Modeling. Modern Methods for Business Research, 295(2), 295-336.

Christine, P., Almazan, G. O., Galangue, P. C. S., David, P., \& Bueno, C. (2017). Total Quality Management (TQM) in Practice at a Private Higher Education Institution in the Philippines. May. https://doi.org/10.17758/uruae.uh09171002 
Fadila, R. N., Lutfiani, E. A., Veronika, N., Rachmanto, D., \& Arfinanti, N. (2020). Efektivitas Pengelolaan Sumber Daya Sekolah Dalam Meningkatkan Mutu Pendidikan. Jurnal Akuntabilitas Manajemen Pendidikan, 8(1), 81-88.

Felestin, \& Triyono, M. B. (2015). The Implementation of Total Quality Management at Vocational High Schools in Indonesia. Research and Evaluation in Education Journal, 1(1), 13-24.

Ghazali, I., \& Latan, H. (2015). Partial Least Squares; Konsep, Teknik, dan Aplikasi menggunakan Program Smart PLS 3.0. Semarang: Badan Penerbit Undip.

Ghozali, I., \& Fuad. (2008). Structural Equation Modeling: Teori, Konsep, dan Aplikasi dengan Program Lisrel 8.80. Badan Penerbit Universitas Diponegoro.

Hair Jr, J. F., Hult, G. T. M., Ringle, C., \& Sarstedt, M. (2016). A Primer on Partial Least Squares Structural Equation Modeling (PLS-SEM). Sage Publications.

Hallinger, P., \& Heck, R. H. (2011). Conceptual and Methodological Issues in Studying School Leadership Effects as a Reciprocal Process. School Effectiveness and School Improvement., 22(2), 149-173. https://doi.org/10.1080/09243453.2011.565777

Jaya, T., Muslim, \& Nuramaliyah. (2016). Internal Control, Total Quality Management, and Audit Committees: Implementation of Good Corporate Governance. Review of Integrative Business and Economics Research., 5(2), $250-259$.

Kanji, G., Malek, A., \& Tambi, B. (1999). Total Quality Management in UK Higher Education Institutions. Total Quality Management., 10(1), 129-153.

Kennerfalk, L. (1995). Changes in Organizational Structure Related to the Implementation of a Total Quality Management Strategy. Luleå University of Technology.

Khurniawan, A. W., Sailah, I., Muliono, P., Maarif, M. S., \& Indriyanto, B. (2020). Analysis of the Effect of School Governance and Total Quality Management on the Effectiveness of Vocational School-based Entreprise. Proceeding on International Conference of Science Management Art Research Technology, 1(1), 1-9.

Khurniawan, A. W., Sailah, I., Muljono, P., Indriyanto, B., \& Maarif, M. S. (2020). An Analysis of Implementing Total Quality Management in Education: Succes and Challenging Factors. International Journal of Learning and Development, 10(2), 44-59.

Kline, R. B. (1991). Latent Variable Path Analysis in Clinical Research: A Beginner's Tour Guide. Journal of Clinical Psychology., 47(4), 471-484.

Liantos, M., \& Pamatmat, F. (2016). Total Quality Management and School-Based Msnagement Practices of School Principlas: Their Implications to School Leadership and Improvement. International Research Journal of Social Sciences., 5(8), 1-7.

Llantos, M. G. B., \& Pamatmat, F. V. (2016). Total Quality Management and School-Based Management Practices of School Principals: Their Implications to School Leadership and Improvement. International Research Journal of Social Sciences, $5(8), 1-7$.

Malhotra, N. K., \& Dash, S. (2016). Marketing Research: An Applied Orientation. Pearson.

Nejad, F. (2014). The Application of Total Quality Management in Teaching-Learning Process. Shahid Rajaee University.

Nurhafifah, N., Djasmi, S., \& Ambarita, A. (2016). Pengaruh Kepala Sekolah Budaya Kinerja Guru terhadap Efektivitas Sekolah. Jurnal Manajemen Mutu Pendidikan, 4(3).

Panigrahi, M. R. (2014). School Effectiveness at Primary Level of Education in Relation to Classroom Teaching. International Journal of Instruction, 7(2), 51-64.

Peak, M. H. (1995). TQM Transforms the Classroom. Management Review, 84(9), 13-18.

Ruinge, M. W., \& Kimani, G. N. (2015). Relationship between Selected Total Quality Management Practices Employed by Public Secondary Schools Principals and Students' Performance in Kenya Certificate of Secondary Education in Kiambu County, Kenya. International Journal of Education and Practice., 3(2), 66-79. https://doi.org/10.18488/journal.61/2015.3.2/61.2.66.79

Salim, N. A. (2017). Peningkatan Efektivitas Pengelolaan Sekolah melalui Penguatan Kemampuan Manajerial Kepala Sekolah. JMSP (Jurnal Manajemen dan Supervisi Pendidikan), 2(1), 8-16.

Sallis, E. (2010). Manajemen Mutu Terpadu Pendidikan (Alih Bahasa: Ahmad Ali Riyadi). Ircisod.

Santoso, S. (2018). Konsep dasar dan Aplikasi SEM dengan AMOS 24. Jakarta: Elex Media Komputindo.

Shahmohammadi, N. (2018). The Impact of Total Quality Management on the Effectiveness of Educational Programs of Karaj First Grade High Schools. Engineering, Technology \& Applied Science Research., 8(1), 2433-2437.

Soghati, A. (2012). The Relationship Between Total Quality Management and Education, Creativity and Productivity of Employees in Department of in Roodan. Islamic Azad University.

Soundararajan, G., Srivastava, P., \& Chinnasamy, G. (2018). Assuring Total Quality Management across Educational Institutions: Evidence from Oman. International Journal of Scientific and Research Publications (IJSRP), 8(4), $218-224$. https://doi.org/10.29322/ijsrp.8.4.2018.p7630 
Stage, F. K., Carter, H. C., \& Nora, A. (2004). Path Analysis: An Introduction and Analysis of a Decade of Research. The Journal of Educational Research, 98(1), 5-13.

Sulfemi, W. B., \& Mayasari, N. (2019). Peranan Model Pembelajaran Value Clarification Technique Berbantuan Media Audio Visual untuk Meningkatkan Hasil Belajar IPS. Jurnal Pendidikan, 20(1), 53-68. https://doi.org/10.33830/jp.v20i1.235.2019

Svensson, M., \& Klefsjö, B. (2006). TQM-Based Self-Assessment in The Education Sector. Quality Assurance in Education.

Taşar, H. H., \& Çelik, M. (2011). Examination of Implementation Level of the Total Quality Management Principles by the Principals and Teachers Functioning at Elementary Schools: The Case of Adiyaman Province. Asian Social Science, 7(9), 33-42. https://doi.org/10.5539/ass.v7n9p33

Teo, T., \& Knine, M. S. (2009). Structural Equation Modeling in Educational research: Concepts and Applications. Sense Publishers.

Wani, I., \& Mehraj, H. (2014). Total Quality Management in Education: An Analysis. International Journal of Humanities and Social Science Invention, 3(6), 71-78.

Wold, H. (1975). Path Models with Latent Variables: The NIPALS Approach. In Quantitative Sociology (pp. 307-357). Seminar Press. 